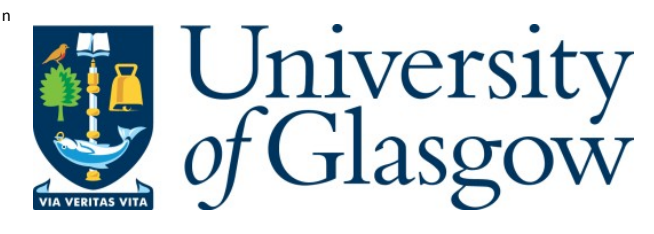

Livingston, M ., Galster, G., K earns, A ., and B annister, J. (2014) Criminal neighbourhoods: does the density of prior offenders encourage others to commit crime? Environment and Planning A , 46 (10). pp. 2469-2488. ISSN 0308-518X

Copyright (c) 2006 Pion

A copy can be downloaded for personal non-commercial research or study, without prior permission or charge

Content must not be changed in any way or reproduced in any format or medium without the formal permission of the copyright holder(s)

http://eprints.gla.ac.uk/93725/

Deposited on: 20 November 2014

Enlighten - Research publications by members of the University of Glasgow http://eprints.gla.ac.uk 


\section{TéEnvironment and Planning}

Criminal Neighbourhoods: Does the Density of Prior Offenders in an Area Encourage Others to Commit Crime?

\begin{tabular}{|r|l|}
\hline Journal: & Environment and Planning A \\
\hline Manuscript ID: & Draft \\
\hline Manuscript Type: & Original Manuscript \\
\hline Keywords: & Offenders, Crime, Neighbourhood effects \\
\hline & \\
\hline
\end{tabular}

SCHOLARONE $^{\text {m }}$

Manuscripts 


\title{
Criminal Neighbourhoods: Does the Density of Prior Offenders in an Area Encourage Others to Commit Crime?
}

\begin{abstract}
Using crime data over a period of a decade for Glasgow, this paper explores whether the density of prior offenders in a neighbourhoods has an influence on the propensity of others to (re)commence offending. The study shows that the number of 'newly active' offenders in a neighbourhood in the current quarter is positively associated with the density of prior offenders for both violent and property crime from the previous two years. In the case of 'newly active' property offenders, the relationship with active prior offenders is only apparent when prior offender counts exceed the median. The paper postulates that intraneighbourhood social mechanisms may be at work to create these effects. The results suggest that policies which concentrate offenders in particular neighbourhoods may increase the number of 'newly active' offenders, and point to evidence of a threshold at which these effects take place.
\end{abstract}

Key words:

Offenders; crime; neighbourhood effects 


\section{Introduction}

There is no doubt that population-adjusted rates of crimes reported to police are higher in deprived neighbourhoods. However, what is not clear is whether concentrated disadvantage makes people who live there more likely to commit crimes. There is a substantial amount of research suggesting that neighbourhoods do have an independent effect on individuals' propensity to commit crimes, but this literature has yet to explore a prime theoretical mechanism through which this "neighbourhood effect" may transpire: the recruitment or influence of 'newly active' offenders by neighbouring prior offenders. To address this gap, we examine the effect of density of prior offenders on the rates of newly active offending in small neighbourhoods in the Scottish city of Glasgow, employing a panel negative binomial model. We find strong neighbourhood effects after threshold densities of prior offenders have been exceeded.

This paper first sets out the literature on neighbourhoods effects and crime and describes the gap in the literature which this research attempts to fill. An account is given of the methods and data used in this research. Results for a basic model with three variants are then described. This is followed with a discussion of the results and how they relate to the literature and what implications this may have for policy makers.

\section{Background}

\section{Potential Mechanisms for Neighbourhoods Affecting Criminality}

Scholarship regarding how neighbourhoods and lifestyles might independently influence an individual's propensity to commit crime falls into one of three categories: (1) the criminal- 
career perspective; (2) the victim perspective; and (3) the context perspective (Miethe and Meier 1994).

Theories taking the "criminal-career" perspective focus on how, through a variety of mechanisms, the peers, family members, or social institutions surrounding individuals influence their potential for becoming an offender, e.g. . the critical role of peers in shaping teen criminal delinquency (Case and Katz 1991). One prominent example of this perspective, the rational choice theory, explains crime as a decision based upon the weighing of costs and benefits of committing a criminal act (Cornish and Clarke 1987; Felson and Boba 2010), an assessment which may be a product of an individual's social development and local norms related to illegal activities.

Cultural explanations of crime, therefore, are also relevant; in particular the notion of 'sociological inheritance', whereby the involvement of parents and elder siblings legitimises an indvidual's participation in offending and violence (Bannister et al 2010; Elias and Scotson 1965). It is also argued that those who place more emphasis on the inter-twining of family and neighbourhood history are more likely to act in accord with that legacy, adopting a particular mode of criminal behaviour (Small 2002), so that individual social and spatial identities become intertwined.

"Victimization" theories focus on the characteristics of potential victims that may put them at an increased risk of experiencing crime, including as accomplices. The routine activity approach posits that "most criminal acts require convergence in space and time of likely offenders, suitable targets, and the absence of capable guardians against crime" (Cohen and Felson 1979, 588). Lifestyle-exposure theory suggests that demographic differences in the 
likelihood of victimization can be attributed to differences in lifestyles that produce differential exposure to dangerous places, times, and others. Thus, different neighbourhood contexts may provide different "proximity to motivated offenders, exposure to high-risk environments, and target attractiveness" (Miethe and Meier 1994, 40). Neighbourhoods containing many young adults or drinking establishments may encourage criminality because of the risk-taking life-styles of residents and an alcohol-induced vulnerability that yields a ready supply of potential victims (Raleigh and Galster 2012).

The "context" perspective suggests that the neighbourhood environment provides multiple signals to likely offenders and shapes space / time patterns through which potential victims pass. Most of the research has investigated cross-sectional differences in social processes across neighbourhoods, including social disorganization, informal social control and collective action, and collective efficacy. Informal social control has been identified empirically as a key inhibitor of neighbourhood crime, and appears strongly correlated with: community social cohesion (Bellair and Browning, 2010); residential stability (Sampson and Groves, 1989; Bellair, 1997; McNulty and Holloway, 2000; Hipp 2007); and home ownership rates (Spelman, 1993; Rohe et al. 2000; Dietz and Haurin, 2003; Herbert and Belsky, 2008; Lindblad, Manturuk and Quercia, 2012).

Comparatively less research has focused on the physical environment's effect on crime, apart from its potential "signalling effect" of social disorder (Wilson and Kelling, 1983). There has been some urban design theorizing though the empirical evidence is equivocal (Bannister 1991), about whether buildings and neighbourhoods providing "defensible spaces" deter crime, or conversely, whether some building types are more vulnerable to crime (Newman, 1972; Poyner, 1983; Taylor, Gottfredson and Browner, 1984). 
Taking a context perspective, the rational-choice view of crime implies that neighbourhoods where potential offenders are presented with perceptibly greater benefits and/or lesser costs or probability of being caught, will generate more crime. Thus, neighborhoods having notably lax law enforcement, many vacant properties as potential venues, or low population densities offering fewer potential reporters of crime, would be expected to encourage the commission of crimes (see Roncek 1981; Spelman 1993; Krivo and Peterson 1996; and Raleigh and Galster (2012).

Structural and cultural explanations for crime are also relevant to the context perspective. Violence can be a product of frustration and rage and an outlet for those from disadvantaged areas with few other legitimate means of expressing themselves or securing a masculine identity (Messerschmidt 2000; Totten 2003); Crime can also be a leisure pursuit to achieve pleasures or 'authentic experiences' not otherwise afforded in deprived areas (Katz 1988; Lyng 2005). Criminal behaviours are understood as part of a 'repertoire' of practices, beliefs and attitudes to enable the attainment of aspirations which are otherwise hard to achieve due to low incomes, poor neighbourhood facilities and restricted mobility (Campbell 1993; Young 1999; Hallsworth 2005), especially where the community lacks structures to control or inhibit such activities (Bannister et al 2012; Sampson et al 1997).

\section{The Challenges of Measuring Causal Relationships}

Despite this well-developed body of criminological theory about why neighbourhoods could have an independent causal impact on residents' propensity to commit crime, most of the empirical evidence has not been definitive. The primary reasons are their failure to account for the statistical biases stemming from potential geographic selection and endogeneity. 
Consider first geographic selection: deprived neighbourhoods may systematically attract individuals who are already more prone to criminal activities (Galster 2008; Hedman and Van Ham 2012). For example, prior offenders gravitate to relatively few neighbourhoods after their release from prison, with a corresponding upsurge in observed crime rates (Hipp and Yates 2009). Similarly, prior offenders may be allocated accommodation in certain areas of welfare housing, often the least popular neighbourhoods. Most past research has consisted of multivariate linear models using cross-sectional data to yield correlations between aggregate crime statistics and neighbourhood characteristics and therefore cannot distinguish empirically neighbourhood selection from neighbourhood effects.

A few studies prove the exception inasmuch as they investigate whether the relationship between neighbourhood crime rates and neighbourhood deprivation is nonlinear. It has long been known that the observation of increasing marginal impacts of higher shares of deprived residents provides strong a priori evidence of a neighbourhood effect because the observation is difficult to explain in terms of selection alone (Manski, 1995). However, whilst Hannon $(2002,2005)$ finds increasing marginal effects, Hipp and Yates (2011) find decreasing marginal effects (except for murder), and Krivo and Peterson (1996) find it depends on whether violent or property crime is considered.

The challenge of endogeneity involves sorting out the degree to which aggregate neighbourhood characteristics influence whether residents commit crimes, or whether aggregate neighbourhood characteristics change as a result of residents committing crimes. In the view of several scholars, Such reciprocity may manifest itself in crime-shaped selective in- and out-migration from a neighbourhood (e.g. younger, single households move in whereas older families with children move out), yielding changes in aggregate population 
characteristics, neighbourhood stability and informal social control, thereby affecting crime rates(Bursik 1988; Felson 2002; Miethe and Meier 1994; Skogan 1990). .

Recently, two studies have probed aspects of these mutually causal relationships using strong statistical models for endogeneity. Hipp, Tita and Greenbaum (2009) found that increased property and violent crime rates predicted increased housing turnover (and, in the case of violent crime, lower home values) in the neighbourhood during the subsequent year, but not vice versa, suggesting that crime was more a driver of neighbourhood change than a response to it. However, Hipp (2010) found that neighbourhood concentrated disadvantage did have a positive relationship with crime rates a decade later and vice versa, suggesting that crime does respond to endogenously produced changes in neighbourhood economic composition. This finding does not, of course, prove that neighbourhoods affect resident criminality, but is consistent with that claim.

In summary, the extant literature reveals the empirical complexities in uncovering the causal impact of neighbourhood characteristics on the propensity of residents to commit crimes. The evidence thus far is suggestive but hardly definitive, due to methodological shortcomings related to geographic selection and endogeneity biases and contradictory findings.

\section{Studying Prior Offenders as a Key Neighbourhood Characteristic}

The density of prior offenders can be considered a key neighbourhood characteristic in the study of place-influenced criminality. It represents both a criminal-career and a context perspective on crime: prior offenders constitute a potentially influential peer group 
for learning and recruitment into crime (the criminal-career view); and, prior offenders may shape the local social context both by establishing norms of criminality and through disrupting or inhibiting processes of informal social control (the context view).

We investigate empirically the relationship between the density of prior criminal offenders in a neighbourhood and the subsequent rate of offending by newly active residents. In neighbourhood effects terms, any statistical relationship observed is likely to represent the manifestation of some unobserved combination of effects transmitted by local peers, role models and/or social networks involving prior offenders and those nearby who have not yet, or recently, offended. Our modelling meets the endogeneity challenge by employing longitudinal data that permit us to specify unambiguously prior conditions and subsequent outcomes. We meet the geographic selection challenge by clearly distinguishing between prior offenders (who may indeed select — or be selected into — their neighbourhoods in a systematic manner based on their unobserved characteristics) and a distinct group of nonrecent-offenders for whom we have no reason to believe will select neighbourhoods on the basis of their share of prior offenders. Moreover, we probe for potential nonlinear relationships to buttress the evidence about causation vs. selection.

We address the following two research questions:

Is the density of prior offenders in a particular neighbourhood during one quarter positively associated with the (population-adjusted) number of newly active offenders in the neighbourhood during the subsequent quarter? 
If there is such an association, does the relationship between density of prior

offenders and number of newly active offenders become significantly stronger past a threshold density of prior offenders?

\begin{abstract}
Whilst our main concern is the criminal-career perspective on criminality, we also incorporate the context perspective in two respects. First, we include elements of the social composition of neighbourhoods in our analysis, including two types of offender (see below), as well as the age structure of the local population - reflecting concerns that young people may be more susceptible to criminal recruitment, a form of 'selective socialisation' (Galster 2007). Second, we consider whether the influence of offenders may operate differently at different levels of neighbourhood deprivation, reflecting arguments in the literature that the more deprived an area is, the greater the necessity (or felt need) to commit crime, and the lower the resistant barriers to that crime within the community.
\end{abstract}

We answer our research questions with a unique dataset and relatively robust analytical strategy. Our dataset involves unprecedented information about individual offenders, what types of crime they committed (permitting the distinction between broad crime types), and when and where the crimes were committed. These data are not a sample; they represent a tabulation of all reported crime in the study area during the period under investigation. This information covers a substantial period: quarterly observations over ten years. Finally, it is tabulated at a fine-grained spatial scale: the datazone level across metropolitan Glasgow, Scotland, which has a mean population nationally of 600 during the period under investigation. 
The panel nature of our data permits us to specify fixed-effect models as an added safeguard against first-time offenders selecting particular neighbourhoods based on unobserved neighbourhood characteristics that might be correlated with the density of prior offenders residing there. The longitudinal nature of our data and the ability to distinguish individuals who constitute a dimension of neighbourhood context (i.e., prior offenders) from those who may be influenced subsequently by this context (i.e., those with no recent criminal record but who subsequently offend) give us the ability to make causal claims with more confidence.

\section{Methods and Data}

\section{Glasgow City}

To answer the research question we have used data from the Scottish city of Glasgow as defined by the Glasgow City Council administrative boundary . Glasgow is a post-industrial city with a population of 598,830 (GRO-Scotland 2012) and considerable problems of deprivation; the city contains 36 per cent of the most-deprived decile of neighbourhoods in Scotland (Scottish Government 2012). Glasgow also has significant levels of crime, with crime rates typically $60 \%$ higher than the national average and $20 \%$ higher than in other Scottish cities (Glasgow Indicators Project 2010). 
Figure 1: Map of Glasgow and surrounding neighbourhoods

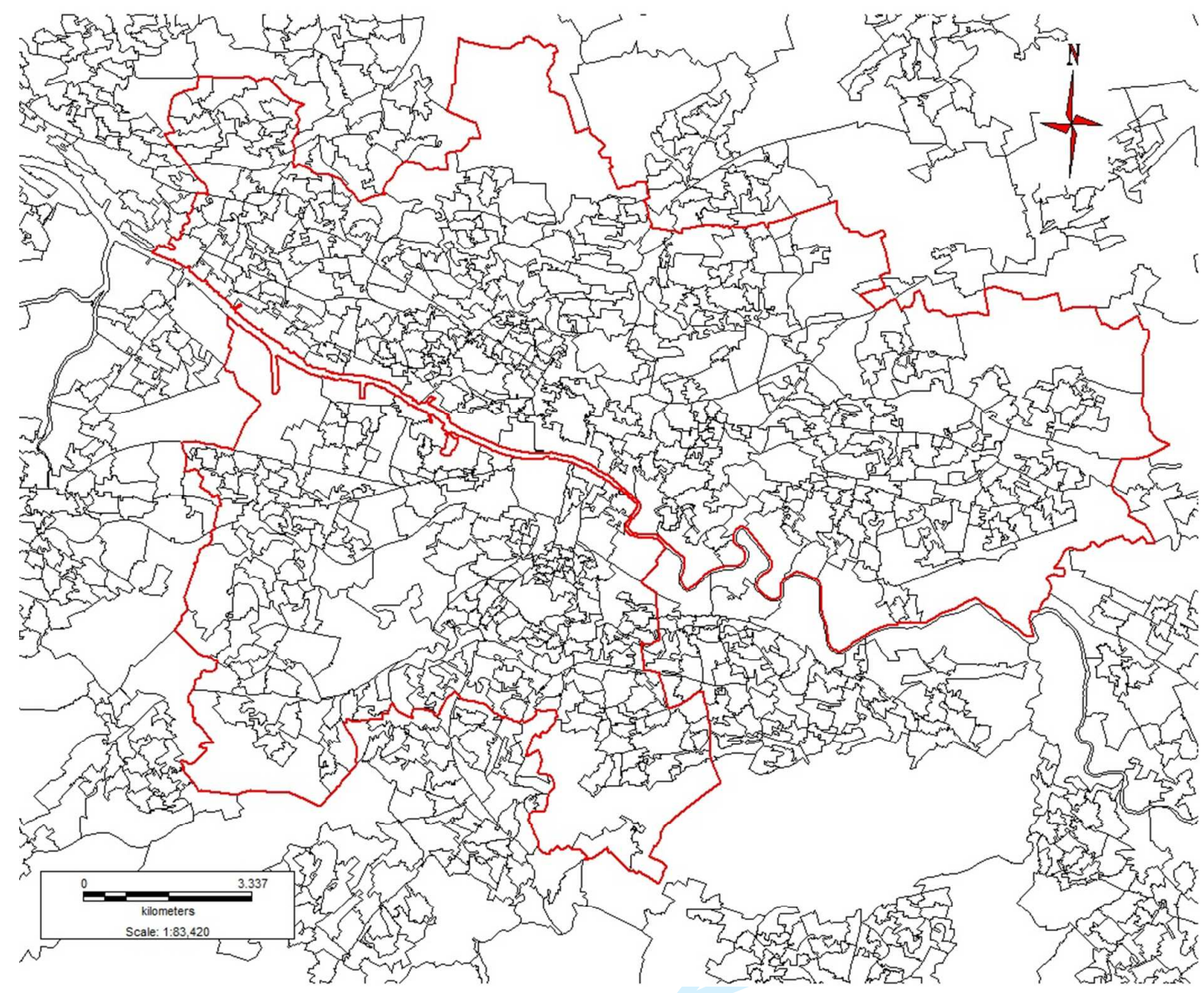

The red lines represent the Glasgow City Council Boundary and the Black lines represent the datazone boundaries. Maps are based on data provided with the support of the Economic and Social Research Council and use boundary material which is copyright of the Crown, Post Office and the EDLINE consortium.

\section{Neighbourhood Scale}

Neighbourhood scale has been defined by datazones which are small scale geographies with average population of 600 people. These were constructed as part of census reporting geographies and are designed to contain households with similar social characteristics (Scottish Government 2006).For the purposes of this project datazones were thought to be an appropriate geography, There are 693 datazones in Glasgow with most of these areas small 
enough to easily walk around in less than 20 minutes. From a practical point of view they are the geographical level at which data is available and the lowest level at which data is available from the Scottish Indices of Multiple deprivation. .

\section{Crime and Offender Data}

Crime data were provided by Strathclyde Police Department for the period (in financial years- April-March), 1998/9 to 2008/9. Two main datasets were used for these analyses. First, the Recorded Crimes Dataset provided data on all crimes in the city, except crimes of a sexual nature. The precise location of each crime was recorded, where known, otherwise the beat location ${ }^{1}$ was given as the geographical location of the crime. Second, the Offenders Dataset provided data on offenders, and their place of residence, where known, at the time of their offending. The recorded Crimes and Offenders datasets link crime and offenders via a unique crime number. Locational data is missing from $20 \%$ of all offenders, similarly for offenders committing violent and property crimes). From these data sets we were able to construct the combined data-set for this research (described below).

Crimes were categorised by the researchers into three groups: all crimes; property crimes; and violent crimes. Although initial analysis examined all crime, for a number of reasons it was felt that this category was too broad. The heterogeneous nature of the group meant that interpretation of results was difficult. It was decided to concentrate analysis on the property

\footnotetext{
${ }^{1}$ Police beats are typically smaller than datazones and in the majority of cases identifying them within a datazone will mean the crime also happened within that datazone.
} 
1

2

3

4

5

6

7

8

9

10

11

12

13

14

15

16

17

18

19

20

21

22

23

24

25

26

27

28

29

30

31

32

33

34

35

36

37

38

39

40

41

42

43

44

45

46

47

48

49

50

51

52

53

54

55

56

57

58

59

60 and violent crime groups. Violent crime mostly comprises murder, assault and weCAPOns offences. Property crime mostly comprises theft, burglary and vandalism (Table 1). 
Table 1: Crime Categories and Types of Crime

\begin{tabular}{|c|c|}
\hline Violent Crime Category & Property Crime Category \\
\hline Murder & Theft from a motor vehicle - not elsewhere classified \\
\hline Possess a firearm with intention to endanger life etc. & Theft by housebreaking - domestic property - dwell \\
\hline Attempted Murder & Theft by housebreaking - domestic property - non-dwell \\
\hline Culpable Homicide - common law & Theft by housebreaking - other property \\
\hline Serious Assault & Housebreaking with intent to steal - dom prop - dwell \\
\hline Robbery & Housebreaking with intent to steal - dom prop - non-dwell \\
\hline Threats and Extortion & Housebreaking with intent to steal - other property \\
\hline $\begin{array}{l}\text { Cruelty - neglecting \& c - to \& unnatural treatment of } \\
\text { children }\end{array}$ & Theft By OLP - not motor vehicle (opening lock fast place) \\
\hline Abduction & OLP with intent to steal - excl motor vehicle \\
\hline Cruel and unnatural treatment of an adult & Attempted OLP with intent to steal - excl motor vehicle \\
\hline Reckless conduct with firearms & Theft By OLP - motor vehicle \\
\hline Mobbing and rioting & OLP with intent to steal - motor vehicle \\
\hline Possession of an offensive weapon & Attempted OLP with intent to steal - motor vehicle \\
\hline Restriction of offensive weapons & In building with intent to steal \\
\hline Carrying of Knives etc S Act 1993 & Theft not elsewhere classified - excl motor vehicle \\
\hline Common Assault & Theft of motor vehicle \& contents incl. taking and driving away \\
\hline Crossbow Offences & Theft by shoplifting \\
\hline Racially aggravated harassment & Theft of pedal cycle \\
\hline Racially aggravated conduct & Attempted theft of a motor vehicle \\
\hline \multirow[t]{7}{*}{ Common assault of an emergency worker } & Reset (receiving or retaining goods, obtained by theft, robbery etc) \\
\hline & Fraud - Including Statutory Fraud \\
\hline & Clandestine removal of boats \\
\hline & Clandestine removal of other property \\
\hline & $\begin{array}{l}\text { Vandalism (includes malicious damage and malicious mischief prior } \\
\text { to April } 2009\end{array}$ \\
\hline & Vandalism (excludes Reckless/Malicious Damage from April 2009) \\
\hline & Malicious Damage \\
\hline
\end{tabular}


Crimes and offender information was located and coded into datazones. We identify a group of Newly Active Offenders (NAOs), defined as those that had not committed a crime in the previous two years but had committed a crime in the current quarter. NAOs were identified in two groups and counts provided: violent NAOs and property NAOs. NAOs will comprise mostly first time offenders (since nearly $90 \%$ of offenders recommit crimes within two years) but also some dormant prior offenders who become active again after a hiatus.

The prevalence of two types of prior offenders were also defined: Currently Inactive Prior Offenders (CCIPOs) defined as having committed a crime sometime in the two years before the current quarter but not in the immediately previous quarter; Currently Active Prior Offenders (CCAPOs) were offenders who had committed crimes in the previous quarter. Rates per 100 persons for both types of offenders were calculated. These data were constructed for each quarter for all datazones for the time period $2000 / 1^{2}$ to $2008 / 9$ giving a total of 35 quarters of data for each datazone. Two years was decided as the period by which to define prior offenders as analysis of the data-set revealed that over $88 \%$ of offenders had reoffended in that period. Increasing the period to 5 years had only limited impact, raising the number of reoffending offenders to $97 \%$ and would have significantly reduced the number of quarters available to the panel analysis. Both CIPOs and CAPOs were identified firstly irrespective of which type of crime they committed, and secondly according to the nature of their most recent crime as either violent or property prior offenders.

\footnotetext{
${ }^{2}$ The period from 1998/9 to 1999/01 were not used as current quarters as full two years of prior data was not available.
} 
We emphasize here that the labels "active" and "inactive" are potentially misleading if interpreted generically. Both sets of prior offenders involve a heterogeneous amalgam of individuals. Nevertheless, on average these two sets can be distinguished by their distributions of values along three dimensions: criminal frequency, type and skill, i.e., how often they commit crimes, what types of crimes they commit, and how skilled are they at avoiding arrest having committed a crime. Collectively, CAPOs denote prior offenders who on average commit crimes more often, and/or commit crimes that because of their intrinsic nature are more likely to get them arrested, and/or are relatively unskilled in avoiding arrest given the type of crime they have committed, hence appearing in the offenders data-set more often. The profile of CIPOs would have all the opposite characteristics including, at the extremes, reformed offenders who will never commit another crime, offenders who commit crimes that because of their intrinsic nature are less likely to get them arrested, and skilled offenders who rarely or never get caught.

\section{Data Caveats}

While the data used in these analyses are unique and of good quality, there are clarifications and caveats that need to be made related to the potential misclassification of offenders. Offenders in our dataset are identified as such by the police. To identify someone as an offender the police must have secured a predetermined level of evidence sufficient to satisfy the procurator fiscal (i.e. local public prosecutor) that a person will be prosecuted. Inevitably there will be some people identified as offenders who are not guilty of the crime in question, and others not identified as offenders that have, in fact, committed crimes. We also know from these data that some types of crime have lower numbers of identified offenders; for instance only about $19 \%$ of burglaries ever identify an offender compared to the crimes 
which involve violence against the person for which nearly $70 \%$ have an identified offender. These issues would affect any analysis conducted on official offender records, but do not necessarily mean that large numbers of offenders are unknown or absent from the data-set, merely that some crimes are unattributed; we also know that most offenders are responsible for multiple crimes, on average 5 crimes or more in our data-set. A second caveat is that although we identify offenders as being either property or violent crime offenders, it is possible that some offenders may have committed both types of offences during their criminal careers.

\section{Neighbourhood Data}

\section{Deprivation}

Neighbourhood deprivation was measured using the \% of people who were income deprived, which is extracted from the Scottish Index of Multiple deprivation (SIMD) and highly correlated with the overall level of deprivation measure $(\mathrm{R}=0.98)$ (Scottish Government 2012). The SIMD income data is for 2002, 2005 and 2008, quarters in these years were each given that year's values. Quarters in the other years were assigned values on the assumption that change in the SIMD was linear over time. These calculations allowed us to apply deprivation to our models as independent variables rather than fixed effects in the models. 


\section{Neighbourhood age profile}

Also added to the panel data is the estimated age and gender distribution of the datazone population for the individual years of the survey. Population Estimates were provided for each year by General Register Office for Scotland (GROS).

\section{Spatial lag variables.}

There is evidence which suggests that crime rates in neighbourhoods might be influenced by the social context in neighbouring areas (Hirschfield 2013). For instance while individuals may travel away from their immediate neighbourhoods to commit crime, evidence suggests that these distances are not great (Meaney, 2004;Hipp and Yates, 2009; Raleigh and Galster, 2012), and where affluent areas border more deprived areas, the former suffer more crime than expected (Bowers and Hirschfield 1999). While datazone borders have been created to represent neighbourhoods, these borders are not physical barriers, and therefore are susceptible to influence from neighbouring datazones. Neighbourhoods are known to be influenced by many factors in nearby areas, like crime (Brantingham and Brantingham, 1984).

It is important that we model these spatial influences, and much has been written about the spatial techniques used to control for these issues (Anselin 1998, LeSage1999). To account for these problems we created equivalent spatial crime lag variables for each of the models, e.g. lag of property crime for models with NAOs who have committed property crime. To do this we identified contiguous datazones for every datazone and then added the average crime rates for the contiguous datazones to the panel data, similar to the methodology used by Hirschfield (2013). We conducted several tests to ascertain the degree to which spatial 
autocorrelation may have influenced our results; in light of these supplemental analyses we are confident that results reported here represent an unbiased effect at the neighbourhood scale $^{3}$.

\section{Analysis}

\section{Panel data}

Our approach has allowed us to construct a series of cross sectional snapshots for each neighbourhood. Taking the first quarter in our data we calculated the offender data (as described above) and added it to the panel dataset, repeating this for all 35 quarters available to us. This provides us with 35 quarters of data for crime, offenders and other neighbourhood characteristics for each of the 693 neighbourhoods.

\section{Fixed effects model}

Using a fixed effect modelling approach to analyse the panel data allows us to control for time-invariant, unobserved heterogeneity across datazones. Parameters of interest are estimated by modelling within-datazone changes over time rather than the between-datazone comparisons, which traditional cross sectional analysis relies on. This technique minimizes the potential bias that may arise if potential first-time offenders select residences based on

\footnotetext{
${ }^{3}$ The usual Moran's I test is invalid here because it would compare residuals spatially across years. We were unable to identify a method for conducting an appropriate spatial autocorrelation test on panel data. Moreover, there are currently no methods for carrying out spatial error or spatial lag modelling for fixed effects negative binomial models using panel data. We thus followed the advice of two leading spatial statisticians, Dr. Julia Koschinsky and Dr. Duncan Lee and tested residuals using Moran's I for each quarter across the 35 quarters. We found that for some (but not all) models there was significant autocorrelation still unaccounted for by the lagged dependent variable. We therefore investigated the scale at which the effects for CIPOs and CAPOs occurred by adding to the model their lags computed for contiguous neighbourhoods. We found that these lags were not significant in any models and results remain largely unchanged for the neighbourhood-level CIPOs and CAPOs, suggesting that these effects are confined within the neighbourhood.
} 
unmeasured heterogeneity across datazones that might be correlated with densities of prior offenders, thus strengthening our confidence that results reflect real effects.

\section{Negative binomial distribution}

As the distribution of both property and violent crime have a negative binomial distribution (Appendix Figure A.1) we have used a negative binomial algorithm for count data for the dependent variables in running the fixed effect model in the Stata statistical software package. The model presumes a Poisson distribution where $\mathrm{Y}_{\mathrm{it}}$ is the independent variable at quarter $\mathrm{t}$ and datazone $\mathrm{i}$, where $\mu_{\mathrm{it}}$ is the expected (mean) value of $\mathrm{Y}_{\mathrm{it}}$ from the model:

$$
\mathrm{Y}_{\mathrm{it} \sim} \text { negative binomial }\left(\mu_{\mathrm{it}}, \alpha\right)
$$

$\ln \left(\mu_{\mathrm{it}},\right)=\mathrm{X}_{\mathrm{it}} \beta$

Spatial correlation is accounted using a simultaneous autoregressive (SAR) type approach, whereby spatially neighbouring values of the dependent variable were included as an additional independent variable. Temporal autocorrelation was accounted for by including the quarter of the data as an independent variable.

\footnotetext{
Where $\mu_{\mathrm{it}}$ is the fitted value (mean) of $\mathrm{Y}_{\mathrm{it}}$ and alpha is a dispersion parameter which relaxes the Poisson assumption of equal mean and variance.
} 


\section{Dependent variables}

Two separate models were run using two different dependent variables, the number of NAOs committing property crimes and the number of NAOs committing violent crimes. The models were then scaled using Stata's offset command, setting the coefficient of datazone population to 1 , which thus allows us to interpret results as adjusted for the datazone population.

\section{Core Model: Independent variables}

A number of independent variables were added to the models (Table 2). Spatial lag variables for crime in the surrounding neighbourhoods are included to account for contamination from surrounding neighbourhoods. CCIPO and CCAPO within the neighbourhood are added as rates per 10,000 of the population. Also added is the datazone population broken down by age and gender (\%). The percentage of people who are income deprived in the neighbourhood is also included. Finally we have also added a set of year-quarter dummy variables to control for any temporal influences upon levels of NAOs, such as macroeconomic cycles and seasonality. 
Table 2 Variables in the core model

\begin{tabular}{|l|c|c|}
\hline Variables used in models & Mean & SD \\
\hline Dependent Variable: & & \\
\hline Number of Property FTOs & 0.87 & 1.18 \\
\hline Number of Violent FTOs & 0.74 & 1.00 \\
\hline Independent Variables: & & \\
\hline NAO spatial lag variable & 39.85 & 21.07 \\
\hline NAO property spatial lag variable & 5.30 & 3.80 \\
\hline NAO Violent spatial lag variable & 5.75 & 4.34 \\
\hline Number of CIPOs & 7.30 & 2.80 \\
\hline Number of CAPOs & 1.82 & 0.93 \\
\hline \% of pop in male age 13-15 & 2.68 & 1.33 \\
\hline \% of pop in male age 16-19 & 4.04 & 2.56 \\
\hline \% of pop in male age 20-24 & 3.99 & 2.46 \\
\hline \% of pop in male age 25-29 & 21.76 & 3.95 \\
\hline$\%$ of pop in male age 30-64 & 5.81 & 2.86 \\
\hline$\%$ of pop in female age 13-15 & 6.97 & 2.60 \\
\hline \% of pop in female age 16-19 & 1.74 & 0.87 \\
\hline \% of pop in female age 20-24 & 2.69 & 1.57 \\
\hline \% of pop in female age 25-29 & 4.38 & 3.14 \\
\hline$\%$ of pop in female age 30-64 & 4.18 & 2.32 \\
\hline \% Income deprivation in population & 23.16 & 3.41 \\
\hline Years and quarter dummies & N/A & N/A \\
\hline Fixed effects: dummies for each datazone & N/A & N/A \\
\hline
\end{tabular}

\section{Variations on the Core Model}

The paper is structured around a core model with a number of variants also presented.

The first variant of the model replaces generic CCIPO and CCAPO rates with more specific rates of CCIPO and CCAPO who have committed either violent or property crimes. These models let us consider if variations in rates of prior offenders who have committed certain types of crime are more strongly associated with variations in NAOs committing the same type of crime. If role modelling, peers, or social networking mechanisms were primarily at play in recruiting new offenders within neighbourhoods, we would expect this to be the case.

The second variant of the core model examines interactions between deprivation in the datazone and active and inactive prior offenders, . We would expect that the prior 
recruitment mechanisms would operate with more potency in deprived places where norms regarding criminality may be more permissive and/or economic necessities may be more compelling. The deprivation, CAPO, and CIPO variables were all rescaled to mean zero and std. dev 1 prior to this interaction model being run.

The third variant of the core model probes for potential non-linearities in neighbourhood effects, exploring whether there are threshold densities for the effect of prior offenders on the level of recruitment of NAOs. Several social-interactive processes within neighbourhoods may only evince efficacy in recruiting new offenders when the number of prior offenders serving as role models or peers exceed a critical amount.

\section{Results}

\section{Core Model: Generic Prior Offenders}

The key results for the core model can be seen at the top of Table $3^{4}$. This shows that the rate of both CIPOs and CAPOs are associated with higher numbers of NAOs for violent crime in a statistically significant way. The strongest effect appears to be for CAPOs, where an increase in the number of active prior offenders in any neighbourhood of $1 \%$ predicts an increase in NAOs of about $6 \%$ after controlling for other factors. Increases in CIPOs also lead to increases in NAOs but the effect is modest compared to the effect of CAPOs.

The results for NAOs committing property crime show a similar pattern with increasing rates of CAPOs being strongly associated with NAOs, with a predicted increase in NAOs of 5\%

\footnotetext{
${ }^{4}$ The full set of results for all variables for all models are given in Appendix Tables A.1-A.4 online.
} 
for every $1 \%$ rise in CCAPOs. The rates of CIPOs do not have a statistically significant effect on the numbers of NAOs committing property crimes.

Two gender-age groups have statistically significant relationships with NAOs committing property crime (see online Appendix Table A.1). Higher percentages of females aged 25-29 years old and 65 years and older are negatively correlated with the numbers of property crime NAOs. These relationships are not replicated in the model examining violent crime.

Table 3 also shows that neighbourhoods with higher rates of income deprivation are also associated with higher numbers of both violent and property crime NAOs. The corresponding relationship between neighbourhood deprivation and reported rates of crime has been widely observed; cf. Hannon (2002, 2005); Hipp and Yates (2009; 2011), Raleigh and Galster (2012). Again we need to recognise that neighbourhoods with deprived populations represent deeper pools of both possible NAOss and victims. They may be areas where comparative shortcomings of security devices and public safety forces may reduce the costs of crime as perceived by potential offenders. The fact that the spatial lag of the given crime type is statistically significant and positive in both cases is as expected, given prior literature (e.g., Hipp and Yates, 2009; Raleigh and Galster, 2012). 


\begin{tabular}{|c|c|c|c|c|c|c|}
\hline \multirow[t]{2}{*}{ Model Type } & \multicolumn{3}{|c|}{ NAOs: Violent Crime } & \multicolumn{3}{|c|}{ NAOs: Property Crime } \\
\hline & Coef. & Std. Err. & $\mathrm{P}>|\mathrm{z}|$ & Coef. & Std. Err. & $P>|z|$ \\
\hline \multicolumn{7}{|c|}{ Core Model: Generic Prior Offenders } \\
\hline Lag_Violent /property NAOs & 0.011 & 0.003 & 0.000 & 0.013 & 0.002 & 0.000 \\
\hline CIPO Rate ${ }^{2}$ & 0.014 & 0.005 & 0.008 & 0.005 & 0.005 & 0.300 \\
\hline CAPO rate ${ }^{2}$ & 0.057 & 0.013 & 0.000 & 0.047 & 0.012 & 0.000 \\
\hline$\%$ Income deprived & 0.006 & 0.002 & 0.001 & 0.016 & 0.002 & 0.000 \\
\hline \multicolumn{7}{|c|}{ First Variant Model: Crime-Specific Prior Offenders } \\
\hline Lag_Violent/Property NAOs & 0.011 & 0.003 & 0.000 & 0.013 & 0.002 & 0.000 \\
\hline CIPO Violent rate ${ }^{2}$ & -0.098 & 0.022 & 0.000 & 0.024 & 0.021 & 0.244 \\
\hline CIPO Property rate ${ }^{2}$ & 0.078 & 0.019 & 0.000 & -0.020 & 0.017 & 0.235 \\
\hline CAPO Violent rate ${ }^{2}$ & 0.035 & 0.043 & 0.423 & 0.047 & 0.041 & 0.248 \\
\hline CAPO Property rate ${ }^{2}$ & 0.105 & 0.038 & 0.006 & 0.078 & 0.035 & 0.025 \\
\hline$\%$ Income deprived & 0.007 & 0.002 & 0.000 & 0.017 & 0.002 & 0.000 \\
\hline \multicolumn{7}{|c|}{ Second Variant Model: Generic Prior Offender x Deprivation Interactions } \\
\hline Lag_Violent/Property NAOs & 0.011 & 0.003 & 0.000 & 0.013 & 0.002 & 0.000 \\
\hline CIPO Rate ${ }^{2}$ & 0.028 & 0.026 & 0.280 & 0.006 & 0.024 & 0.794 \\
\hline CIPO *Deprivation & 0.030 & 0.019 & 0.111 & 0.014 & 0.017 & 0.395 \\
\hline CAPO rate ${ }^{2}$ & 0.053 & 0.019 & 0.005 & 0.056 & 0.018 & 0.002 \\
\hline CAPO *Deprivation & 0.010 & 0.015 & 0.489 & -0.004 & 0.014 & 0.781 \\
\hline$\%$ Income Deprived & 0.061 & 0.034 & 0.075 & 0.241 & 0.031 & 0.000 \\
\hline \multicolumn{7}{|c|}{ Third Variant Model: Generic Prior Offender Thresholds } \\
\hline Lag_Violent/Property NAOs & 0.011 & 0.003 & 0.000 & 0.013 & 0.002 & 0.000 \\
\hline CIPO Rate ${ }^{2}$ & 0.005 & 0.018 & 0.792 & 0.003 & 0.017 & 0.874 \\
\hline CIPO median spline & 0.010 & 0.019 & 0.598 & 0.002 & 0.018 & 0.915 \\
\hline CAPO rate $^{2}$ & 0.024 & 0.043 & 0.582 & -0.066 & 0.042 & 0.114 \\
\hline CAPO median spline & 0.037 & 0.047 & 0.429 & 0.127 & 0.045 & 0.005 \\
\hline$\%$ Income deprived & 0.006 & 0.002 & 0.001 & 0.016 & 0.002 & 0.000 \\
\hline
\end{tabular}

First Variant Model: Crime-Specific Prior Offenders

In the first variant models we substituted non-crime-specific CIPO and CAPO rates with four crime-specific variables: CIPOs \& CAPOs who had committed violent crimes; and, CIPOs and CAPOs who had committed property crimes. Results are presented in the second section of Table 3. 
In the violent NAO model the corresponding (i.e. violent crime) CAPO variable is not significant but CAPOs whose last crime was a property crime are significantly associated with an increase in violent NAOs. CIPOs whose last crime was a property crime are also significantly associated with an increase in violent NAOs. Unexpectedly, corresponding (i.e. violent crime) CIPOs are significantly associated with lower levels of violent NAOs. We will consider the reasons for this result in the discussion. Overall, the combined positive effects of the two property prior offender variables upon first time violent offending is greater than the negative effect of the inactive violent prior offender variable, so that the overall effect is that the presence of prior offenders in the area has a positive impact upon first time violent offending (consistent with the core model),

The first variant property model is very similar to the core model with a slightly stronger and significant positive association between active prior property offenders and newly active property offenders. No category of other prior offenders has a significant association with NAOs in the model. The only other change from the core property NOA model is that females aged 25-29 are no longer significantly associated with a decrease in NAOs (see online Appendix Table A.2).

\section{Second Variant Model: Interactions between Prior Offenders and Deprivation:}

The second variant of the core model examines the interaction effect of deprivation in the neighbourhood and prior offenders both inactive and active. In both types of NAO crime models, deprivation does not significantly interact with CIPOs or with CAPOs. The main 
effect of CIPO becomes statistically insignificant in the violent NAO model as does the impact of deprivation. Unlike in the violent model, deprivation remains significant in the property NAO model.

\section{Third Variant Model: Non-linearities in the Prior Offender:-NAO relationship}

In the third variant of the model we specify spline variables to investigate the existence of non linearities and thresholds. We experimented by using quartiles of observed rates of CIPOs and CAPOs as the knots for the splines ${ }^{5}$. This specification allows us to test whether the relationship between the CIPO and CAPO variables and NAOs changes between each of these knots. ${ }^{6}$ These experiments revealed that a much simpler specification involving only one spline knot at the median captured the only observed nonlinearities. Results from this analysis can be seen in the final section of Table 3 .

The most striking result is a strong threshold result for CAPOs at its median (median CAPO rate $=1.705$ per 100 ) in the NAO property crime model. This suggests that density of active offenders has little or no effect on newly active offending in a neighbourhood until the density reaches the median, at which point there is a significantly large marginal effect that remains unaltered thereafter. There were no similar thresholds observed for the relationship between CIPOs and NAOs in any of our experimental spline specifications.

\footnotetext{
${ }_{6}^{5}$ Knots are the break points in the distribution used for analysis.

${ }^{6}$ In each spline range past the baseline the test for statistical significance involves the null hypothesis that the slope past the given knot is no different from the slope accumulated across all prior (smaller) knots.
} 


\section{Discussion}

Our analysis of Glasgow data indicates that the population-adjusted rate of prior criminal offenders residing in a datazone during one quarter is positively associated with the number of residents who become newly active violent or property crime offenders during the subsequent quarter. Note that most 'newly active' offenders will in fact be first-time offenders, but that this group will also include prior offenders who have been dormant or inactive for some time. The relationship is strongest for the most currently active prior property crime offenders for newly active offenders who commit violent or property crime. The positive relationship between active prior property crime offenders and newly active property offenders is evident only when the former exceeds the median. There is also a weaker positive relationship between inactive prior property offenders and newly active violent offenders, but no apparent relationship with newly active offenders committing property crime. In this discussion we: (1) indicate why we think these relationships reflect causal connections; (2) reflect on what underlying mechanisms might be at play; and (3) draw policy implications.

\section{Selection and Endogeneity Challenges Revisited}

We believe that our modelling has surmounted the challenges of geographic selection and endogeneity, and that the foregoing statistical associations represent real relationships. 
Regarding selection, our fixed-effects specification controlled for idiosyncratic features of our datazones (such as aspects of the built and physical environment, local police enforcement) that may have influenced both the numbers of prior offenders residing there and the numbers of first-time offenders and may be reasonably assumed time-invariant over the course of our analysis period. Moreover, we can discern no plausible reasons why unobserved characteristics of prior offenders would lead them to move into datazones that offer larger pools of potential offenders and would also positively correlate with the probabilities that such potentials will turn to actual offenders. An unexplored issue, however, is the fact that offenders may return to areas in which they have strong family connections which they could use for influence or recruitment into crime. Indeed, the emerging field of neighbourhood histories is one that could be usefully applied to studies of offending as well as of poverty (Van Ham et al 2012).

Regarding endogeneity, we believe that our explicit lag structure offers some assurance that we are measuring the effect of neighbouring prior offenders on the chances of first-time offending and not vice versa. Indeed, we do not find persuasive reasons to posit such reverse causality.

\section{Potential Causal Mechanisms}

The results show that the types of crimes committed by NAOs appear to be influenced differently by the types of prior offenders, and that these differences may give us an indication of which mechanisms might be most influential for different crimes. We argue that 
the mechanisms most influencing property crimes and violent crimes are likely to be different.

Most property crime is likely to require skills that need to be learned (eg burglary) or to be perpetrated by groups (eg. some types of vandalism). This learning and association is most likely to come from, and be with peers and members of local social networks. Our finding that active prior offenders who commit property crimes are influential on the number of property newly active offenders is consistent with this view that networking processes and peer influences are important for property crime. This may enable opportunities for the enactment of property crime within the local context to be increasingly taken advantage of, whilst altering the view of the risks involved. The threshold results for newly active property offenders are supportive of our postulation that CAPOs exert their influence in recruiting NAOs through social interactive processes within the neighbourhood. A few CAPOs in the neighbourhood may indeed constitute potentially "undesirable friends" and “inappropriate role models" for neighbours who have never committed crime, but these few CAPOs may represent only an exceptional, “deviant” peer in a neighbour's otherwisenoncriminal social network. As the number of CAPOs in a neighbourhood becomes substantial, however, their marginal power to create a critical mass of criminal peers, broadcast their criminal expertise, and infiltrate more and more noncriminal local social networks may expand disproportionately.

While newly active property offenders will be influenced by their social networks, the factors that make an individual react with, or perpetrate, violence are likely to be due to a deeper socialisation that may come from the culture and norms of the neighbourhood. The fact that we find no threshold effects for the violence model further supports our argument 
that these sorts of crimes are more subject to neighbourhood socialisation mechanisms which rely less on a critical mass of prior offenders. Consistent with our view, we found that both active and inactive prior offenders who committed property crime (both recently and longer ago) appear to influence the probability of violent NAOs. This might be due to such prior offenders carrying with them norms regarding lawlessness that permeate the surrounding neighbourhood. This view is strengthened by recognizing that an unknown proportion of prior property offenders have been violent offenders in their history. Furthermore, the fact that property crime is far more common than violent crime (by a factor of 2 or 3 to 1 , depending on the year) supports the view that high levels of property crime may be symptomatic of high levels of criminality in general, and that prior property offenders may affect first-time violent offenders through their influence on criminal norms and culture in the area.

Our findings in relation to the role of violent prior offenders are interesting and unusual, and worthy of further consideration. But first we must recognise some limitations to what we have been able to analyse. It is likely that some violent offenders also commit property crimes such that the distinction between the two is not watertight. Further, we have not examined the part played by offenders who commit different types of violent crime, some of which will result, for example, in custodial sentences which remove offenders from the neighbourhood for periods of time. Violent crime may also be individual or group based, which again we have not been able to separate.

Nevertheless, the fact that CIPOs whose last known offence was a violent one were found to have a strong negative relationship with violent NAOs, in contrast to the positive 
relationships between property prior offenders and FTOs, suggests that different processes may be at work in relation to violent crime within neighbourhoods and that context may not play the same role as it does for property crime.

It may be that prior violent offenders exert a form of social control over others in the neighbourhood. The crimes in the violent crime category include severe crimes associated with quite extreme offending and may represent the presence of serious offenders who wish to exercise control over their 'turf', and to control the activities or influence of others who are potentially perceived as a threat. This would be consistent with group-based violence associated with territoriality (Goldson 2011; Pitts 2008). A further, related explanation lies in the cultural and 'sociological inheritance' view of violence. Violent offenders are a much smaller group within any neighbourhood than property offenders, hence lessening the role of social networks as a mechanism, but highlighting the role of 'cultural frames' of violence shared within tight circles of kith and kin. Thus, violent crime may become the preserve of a dominant, closely bonded group within an area, such that similar criminal activity by others is not heightened.

Finally, neighbourhoods with higher percentages of women who are between 25-29 and over 65 years of age were found to have lower numbers of newly active offenders who commit property crime. This may reflect the fact that females are less likely to be victims of crime but are also less likely to become offenders (Graham and Bowling, 1995; Soothill et al, 2002; Davies, 2011). It is possible that females, and older females in particular, act as agents of social control and that this helps to explain the significant negative relationships in the 
models. However, these relationships only seemed to exist with relation to property crime and not violent crime

\section{Policy Implications}

Besides its importance in casting light on potential causal mechanisms, our finding of thresholds for percentages of active prior property offenders holds broader significance for research and policy related to crime and neighbourhoods, arguing against segregating the disadvantaged. Several strands of research have indicated that context thresholds should be adopted as a working hypothesis for many neighbourhood effect outcomes, including criminality (Galster, 2003; 2008). Krivo and Peterson (1996) and Hannon (2002, 2005) have found distinct thresholds and/or increasing marginal effects of neighbourhood poverty rates on neighborhood crime rates in U.S. census tracts, though recently Hipp and Yates (2011) have provided contrary evidence. Galster et al (2003) found that subsidized housing complexes for special needs residents only created negative crime spillovers for their environs when their density surpassed a threshold. Ellen, Lacoe and Sharygin (2012) found that crime rose only after active foreclosures or real estate (lender)-owned properties reached a threshold number on the blockface. Popkin et al. (2012) found that crime rates in neighbourhoods only rose in response to in-migration of former public housing residents who had been displaced from their demolished developments when their share exceeded a threshold.

This set of consistent results points to the same clear policy implication: interventions that succeed in restraining neighbourhood contexts before they exceed thresholds past which negative consequences ensue can lead to enhancements in overall well-being for society (Galster and Zobel, 1998; Galster, 2002). In the particular case of this study, our findings 
suggest that policy makers should try to avoid residential concentrations of those who have recently offended, as the greater the density of offenders in any one neighbourhood, the more likely that some other residents will also become offenders for the first time.

This message is one that should inform an adjustment to how public agencies think about policies for the resettlement of offenders. Currently, most UK policy about why and how offenders coming out of custody should be resettled in the community concerns the impact that homelessness has upon re-offending rates (SEU 2002; HMI 2001), and the importance of settled accommodation for the future progress of the individual (NOMIS 2008), and access to support services (Kirkwood and Richley 2008). Indeed, the difficulties for offenders in accessing private and social housing (Homeless Link 2011) have been highlighted as partly due to the fact that offenders are often unable to demonstrate a local connection as required under housing legislation and are therefore "unlikely to be eligible for accommodation in an area other than the one from which they come' (Gojkovic et al 2012).

But whereas those working in the resettlement sector see this housing circularity as problematic for individuals who might wish to start a new life elsewhere, our research indicates that this kind of 'lock-in' effect whereby the housing system tends to produce, directly or indirectly, concentrations of offenders in particular places, rather than a dispersal of offenders, can also be problematic for communities and for the criminal justice system as a whole if it results in more newly active offenders being recruited into criminality than would otherwise be the case. Thus, we would argue that the community dimension to the resettlement of offenders deserves greater attention from policy-makers and practitioners than has hitherto been the case. 


\section{Conclusions}

This research offers an original contribution to the literature about the impact of neighbourhood on individuals, by examining the effects over time of offender densities. Using a large, longitudinal data-set of all crimes and offenders within a city over a ten year period, it highlights that those living in areas with higher levels of prior offenders are more at risk of subsequently becoming active offenders themselves. While we can only postulate about the possible mechanisms for these relationships we can be clear from this analysis that these relationships exist and that they are strong and probably causal. Our panel analysis with lagged variables has allowed us keep neighbourhoods (datazones) fixed throughout the analysis and does not require us to rely on observations across datazones. This strengthens our conviction that these relationships are likely to be genuinely causal and that they add substantially to the neighbourhood effects literature.

The paper provides important evidence for policy makers who are concerned with reducing the numbers of offenders and subsequently the amount of crime being committed. Not only is there evidence which suggests that concentrating offenders into particular neighbourhoods will have undesirable consequences for the number of subsequent newly active offenders, but it has been demonstrated that there is a threshold beyond which the impact of local offenders increases. 


\section{REFERENCES}

Anselin, L. (1998). Exploratory spatial data analysis in a goecomputational environment. In P. Longley, S. Brooks, B. Macmillan, \& R. McDonnell (Eds), GeoComputation: A primer (pp77-94). New York: Wiley.

Anselin, L. Cohen, J. Cook, D, Gorr, W. and Tita, G. (2000) Spatial analysis of crime. In Measurment and Analysis of Crime and Justice Volume 4 Criminal Justice 2000.

Washington, DC. U.S Department of Justice.Brantingham, P. J. and Brantingham, P. L. 1984. Patterns in Crime, New York: MacMillan.

Bannister,J. et.al. (2010) Troublesome Youth Groups, Gangs and Knife Carrying in Scotland. Edinburgh: Scottish Government.

Bannister,J., Kintrea,K. and Pickering,J. (2012) 'Young people and violent territorial conflict: exclusion, culture and the search for identity', Journal of Youth Studies, doi: 10.01080/13676261.2012.725835.

Bellair, P. (1997). Social Interaction and Community Crime, Criminology 35(4): 677-703.

Bellair, P. and Browning, C. (2010). Contemporary disorganization research: An assessment and further test of the systemic model of neighborhood crime. Journal of Research in Crime and Delinquency, 47(4): 496-521. doi:10.1177/0022427810375578.

Bowers,K.J. and Hirschfield,A. (1999) 'Exploring links between crime and disadvantage in north west England: an analysis using Geographical Information Systems', International Journal of Goegraphical Information Science, 13:2, 159-184.

Brantingham,P.J. and Brantingham,P.L. (1984) Patterns in Crime. New York: MacMillan. 
Bursik, R. (1988). Social Disorganization and Theories of Crime and Delinquency: Problems and Prospects. Criminology 26: 519-51.

Campbell,B. (1993) Goliath: Britian's Dangerous Places. London: Methuen.

Case, A., and Katz, L.. 1991. The Company You Keep: The Effects of Family and

Neighborhood on Disadvantaged Youth. NBER Working Paper 3705. Cambridge, MA:

National Bureau of Economic Research.

Cohen, L. and Felson, M. (1979). Social change and crime rate trends: A routine activity approach. American Sociological Review 44 (4): 588-608.

Cornish, D. and Clarke, R. (1987). Understanding crime displacement: An application of rational choice theory. Criminology 25 (4): 933-948.

Davies, P. 2011. Gender, Crime and Victimisation, Sage: London.

Dietz, R. and Haurin, D (2003). The social and private microlevel consequences of homeownership. Journal of Urban Economics, 54(3): 401-450.

Elias,N. and Scotson,J.L. (1965) The Established and the Outsiders: a Sociological Enquiry into Community Problems. London: Sage.

Ellen, I., Lacoe, J. and Sharygin, C. (2012). “Do Foreclosures Cause Crime?” Journal of Urban Economics 74, 59-70..

Ellen, I., Michael, L., and O’Regan, K (2012). “American Murder Mystery Revisited: Do Housing Voucher Households Cause Crime?’ Housing Policy Debate, 22(4): 551-572.

Felson, Marcus (2002). Crime and Everyday Life. Thousand Oaks, CA: Sage.

Felson, M., and Boba, R. (2010). Crime and everyday life. 4th Edition. Thousand Oaks, California: SAGE Publications. 
Freedman, M., and Owens, E. (2011). “Low-Income Housing Development and Crime.” Journal of Urban Economics 70(2-3): 115-131.

Galster, George (2002) “An Economic Efficiency Analysis of Deconcentrating Poverty Populations," Journal of Housing Economics 11 (4): 303-329.

Galster, G (2003) “Investigating Behavioral Impacts of Poor Neighborhoods: Towards New Data and Analytical Strategies," Housing Studies 18 (6): 893-914.

Galster, G. (2008). Quantifying the Effect of Neighbourhood on Individuals: Challenges, Alternative Approaches and Promising Directions, Journal of Applied Social Science Studies [Schmollers Jahrbuch/Zeitscrift fur Wirtschafts- und Sozialwissenschaften] 128, 7-48.

Galster,G. (2007). 'Neighbourhood social mix as a goal of housing policy: a theoretical analysis', European Journal of Housing Policy, 7:1, 19-43.

Galster, George, Kathryn Pettit, Anna Santiago, and Peter Tatian (2002). "The Impact of Supportive Housing on Neighborhood Crime Rates," Journal of Urban Affairs 24, 289-315.

Galster, G,, Tatian, P. Santiago, A. Pettit, K and Smith, R. (2003) Why NOT in My Back Yard? The Neighborhood Impacts of Assisted Housing. New Brunswick, NJ: Rutgers University Center for Urban Policy Research / Transaction Press.

Galster, G. and Zobel, A. (1998). "Will Dispersed Housing Programs Reduce Social Costs in the U.S.?" Housing Studies 13 (5): 605-622

Glasgow Indicators Project (2010) Overall Crime Rate. See: http://www.understandingglasgow.com/indicators/community_safety/overall_crime_rate Gojkovic,D, Mills,A. and Meek,R. (2012) Accommodation for Ex-Offenders: Third Sector Housing Advice and Provision, Working Paper 77. Birmingham: Third Sector Research Centre, University of Birmingham. 
Goldson,B. Ed. (2011) Youth in Crisis? 'Gangs', Territoriality and Violence. London: Routledge.

Graham, J. and Bowling, B. 1995 Young People and Crime, Research and Statistics Department, Home Office: Lomndon.

Griffiths, E. and Tita, G. (2009). "Homicide In and Around Public Housing: Is Public Housing a Hotbed, a Magnet, or a Generator of Violence for the Surrounding Community?" Social Problems 56(3): 474-493.

GRO-Scotland (2012) Glasgow City Council Area Demographic Factsheet. Edinburgh: General Register Office, Scotland.

Hallsworth,S. (2005) Street Crime. Cullompton, Devon: Willan Publishing.

Hannon, L. (2002). Criminal opportunity theory and the relationship between poverty and property crime. Sociological Spectrum 22: 363-81.

Hannon, L. (2005). Extremely poor neighborhoods and homicide. Social Science Quarterly 86: 1418-34.

Harcourt, B. and Ludwig, J. (2006). Broken windows: New evidence from New York City and a five-city social experiment. The University of Chicago Law Review 73 (2006): 271320.

Hedman, L., (2011). The Impact of Residential Mobility on Measurements of Neighbourhood Effects, Housing Studies 26, 501-519.

Hedman, L. and Galster, G. (2012) Housing Studies 27, [forthcoming]

Hedman, L. and van Ham, M. (2012). Understanding Neighbourhood Effects: Selection Bias and Residential Mobility. Pp. 79-99 in M. van Ham, D. Manley, N. Bailey, L. Simpson and 
D. Maclennan (Eds.), Neighbourhood Effects Research: Theory and Evidence. Dordrecht: Springer.

Herbert, C. and Belsky, E. (2008). The homeownership experience of low-income and minority households: A review and synthesis of the literature. Cityscape, 10(2): 5-60.

Her Majesty's Inspectorate of Prisons (2001) Through the Prison Gate: A Joint Thematic Review by HM Inspectorates of Prisons and Probation. London: HMI.

Hipp, John (2007). Income Inequality, Race and Place. Criminology 45(3): 665-697.

Hipp, John (2010). A Dynamic View of Neighborhoods: The Reciprocal Relationship between Crime and Neighborhood Structural Characteristics. Social Problems. 57(2): 205230.

Hipp, J., Tita, G. and Greenbaum, R (2009). Drive-bys and Trade-ups: Examining the Directionality of the Crime and Residential Instability Relationship. Social Forces 87(4): $1777-1812$.

Hipp, J. and Yates, D. (2009). Do returning parolees affect neighborhood crime? A case study of Sacramento. Criminology 47 (3): 619-656.

Hipp, J. and Yates, D. (2011). Ghettos, Thresholds, and Crime. Criminology 49(4): 955990.

Hirschfield,A. (forthcoming 2013) 'How places influence crime: the impact of surrounding areas on neighbourhood burglary rates in a British city', Urban Studies.

Homeless Link (2011) Better Together: Preventing Reoffending and Homelessness. London: Homeless Link.

Immergluck, D. and Smith, G. (2006). The Impact of Single-Family Mortgage Foreclosures 
on Neighbourhood Crime, Housing Studies 21(6): 851-866.

Katz, C., Wallace, D. and Hedburg, E.C. (2011). A Longitudinal Assessment of the Impact of Foreclosure on Neighborhood Crime, Journal of Research in Crime and Delinquency, published online Dec. 26, 2011; doi: 10.117/022427811431155.

Katz,J. (1988) Seductions of Crime: Moral and Sensual Attractions in Doing Evil. New York: Basic Books.

Kirkwood,S. and Richley,T, (2008) ‘Supported accommodation services for offenders', SCOLAG Journal, June, 141-142.

Krivo, L. and Peterson, R. (1996). Extremely disadvantaged neighborhoods and urban crime. Social Forces 75 (2): 619-648.

LeSage, J. (1999). The theory and Practice of Spatial Economics. Toledo. University of Toledo.

(http://citeseerx.ist.psu.edu/viewdoc/download?doi=10.1.1.111.4233\&rep=rep1\&type=pdf)

Lindblad, M, Manturuk, K. and Quercia, R. (2012). Sense of Community and Informal Social Control Among Lower Income Households: The Role of Homeownership and Collective Efficacy in Reducing Subjective Neighborhood Crime and Disorder American Journal of Community Psychology DOI: 10.1007/s10464-012-9507-9

Lyng,S. (2005) 'Sociology at the edge: social theory and voluntary risk taking', in S.Lyng Ed. Edgework: The Sociology of Risk Taking. New York: Routledge.

Manski, C. (1995). Identification Problems in the Social Sciences. Cambridge, MD: Harvard University Press.

Meaney, R. 2004. Commuters and Marauders: An examination of the spatial behaviour of 
serial criminals, Journal of Investigative Pyschology and Offender Profiling, 1: 121-137.

Messerschmidt,J. (2000) Nine Lives: Adolescent Masculinities, the Body and Violence. Oxford: Westview Press.

McNulty, T. and Holloway S. (2000). Race, Crime and Public Housing in Atlanta. Social Forces 79(2): 707-729.

Miethe, T. and Meier R.(1994). Crime and its Social Context: Toward an Integrated Theory of Offenders, Victims, and Situations. Albany: State University of New York Press.

Newman, O. (1972). Defensible Space. NY: MacMillan.

National Offender Management Service (2008) Reducing Re-Offending: Housing and Housing Support Resource Pack. London: NOMIS.

Pitts,J. (2008) Reluctant Gangsters: the Changing Face of Youth Crime. Devon: Willan Publishing.

Popkin, S, Rich, M. Hendey, L. Parilla,J. and Galster, G (2012). "Public Housing Transformation and Crime: Making the Case for Responsible Relocation.” Cityscape 14(3): 137-160.

Poyner, B. (1983). Design Against Crime- Beyond Defensible Space. Woburn, MA: Butterworth-Heinemann.

Raleigh, E and Galster, G. 2012. "Neighborhood Disinvestment, Abandonment and Crime Dynamics." Paper presented at ACSP Meetings, Cincinnati, OH, Nov.

Rohe, William, Shannon Van Zandt and George McCarthy (2000). The social benefits and costs of homeownership: A critical assessment of the research. Washington, DC: Research Institute for Housing American Report 
Roncek, D. (1981). Dangerous places: Crime and residential environment. Social Forces 60. (1): 74-96.

Sampson, R., and William G. (1989). Community Structure and Crime: Testing Social disorganization theory. American Journal of Sociology 94(4): 774-802

Sampson, R., Raudenbush S., and Earls, F. (1997). Neighborhoods and violent crime: A multilevel study of collective efficacy. Science, 277(5328): 918-924.

Santiago, A., Galster G., and Pettit, K. (2003). "Neighborhood Crime and Scattered-Site Public Housing," Urban Studies 40, 2147-2163

Scottish Government (2012) Scottish Index of Multiple Deprivation 2012. Edinburgh: The Scottish Government.

Skogan, W. (1989). Communities, Crime, and Neighborhood Organization. Crime and Delinquency 35: 437-57.

Skogan, W. (1990). Disorder and Decline: Crime and the Spiral of Decay in American Neighborhoods. New York: Free Press.

Small,M.L. (2002) 'Culture, cohorts and social organisation theory: understanding local participation in a Latino housing project', American Journal of Sociology, 108:1, 1-54.

Social Exclusion Unit (2002) Reducing Re-offending by Ex-Prisoners. London: SEU.

Soothill, k., Francis, B. and Fligestone, R. 2002. Patterns of Offending Behaviour: A New Approach, Findings 171, Research, Development and Statistics Directorate, Home Office: London.

Spelman, W. (1993). Abandoned buildings: Magnets for crime? Journal of Criminal Justice 21: 481-495. 
Taylor, R., Gottfredson, S. and Browner, S. (1984). Block Crime and Fear: Defensible Space, Local Social Ties, and Territorial Functioning. Journal of Research in Crime and Delinquency 21: 303-331.

Totten,M. (2003) 'Girlfriend abuse as a form of masculinity construction among violent, marginal male youth', Men and Masculinities, 7:6, 70-92.

Van Ham,M., Hedman,L., Manley,D. and Coulter,R. (2012) 'Intergenerational transmission of neighbourhood poverty in Sweden: an innovative analysis of individual neighbourhood histories', IZA DP 6572. Bonn: Institute for the Study of Labour (IZA).

Wilson, J. and Kelling, G. (1983). "Broken Windows.” The Atlantic Monthly (March): 2938.

Young,J. (1999) The Exclusive Society: Social Exclusion, Crime and Differences in Late Modernity. London: Sage. 
Table A1: First time offenders committing violent/property crime in relationship to all prior offenders (Core model) ${ }^{1}$

\begin{tabular}{lrrr|rrr}
\hline & \multicolumn{3}{c|}{ Violent } & \multicolumn{3}{c}{ Property } \\
& Coef. & Std. Err. & $P>|z|$ & Coef. & Std. Err. & $P>|z|$ \\
\hline Lag_Violent /property NAOs & $\mathbf{0 . 0 1 1}$ & $\mathbf{0 . 0 0 3}$ & $\mathbf{0 . 0 0 0}$ & $\mathbf{0 . 0 1 3}$ & $\mathbf{0 . 0 0 2}$ & $\mathbf{0 . 0 0 0}$ \\
CIPO Rate & $\mathbf{0 . 0 1 4}$ & $\mathbf{0 . 0 0 5}$ & $\mathbf{0 . 0 0 8}$ & 0.005 & 0.005 & 0.300 \\
CAPO rate & $\mathbf{0 . 0 5 7}$ & $\mathbf{0 . 0 1 3}$ & $\mathbf{0 . 0 0 0}$ & $\mathbf{0 . 0 4 7}$ & $\mathbf{0 . 0 1 2}$ & $\mathbf{0 . 0 0 0}$ \\
\% Males aged 13_15 & 0.007 & 0.017 & 0.661 & -0.017 & 0.016 & 0.296 \\
\% Males aged 16_19 & 0.013 & 0.013 & 0.313 & -0.008 & 0.012 & 0.506 \\
\% Males aged 20_24 & -0.014 & 0.011 & 0.205 & -0.011 & 0.010 & 0.275 \\
\% Males aged 25_29 & -0.002 & 0.011 & 0.844 & -0.004 & 0.010 & 0.667 \\
\% Males aged 30_64 & 0.004 & 0.008 & 0.626 & 0.010 & 0.007 & 0.171 \\
\% Males aged 65Over & -0.014 & 0.016 & 0.371 & -0.014 & 0.015 & 0.349 \\
\% Females aged 13_15 & 0.009 & 0.018 & 0.609 & 0.001 & 0.017 & 0.956 \\
\% Females aged 16_19 & -0.004 & 0.013 & 0.787 & -0.006 & 0.012 & 0.618 \\
\% Females aged 20_24 & 0.011 & 0.011 & 0.334 & -0.005 & 0.010 & 0.647 \\
\% Females aged 25_29 & 0.010 & 0.012 & 0.441 & $-\mathbf{0 . 0 2 3}$ & $\mathbf{0 . 0 1 1}$ & $\mathbf{0 . 0 4 2}$ \\
\% Females aged 30_64 & -0.013 & 0.010 & 0.177 & -0.008 & 0.009 & 0.385 \\
\% Females aged 65Over & -0.015 & 0.011 & 0.173 & $\mathbf{- 0 . 0 2 1}$ & $\mathbf{0 . 0 1 0}$ & $\mathbf{0 . 0 3 1}$ \\
\% Income deprived & $\mathbf{0 . 0 0 6}$ & $\mathbf{0 . 0 0 2}$ & $\mathbf{0 . 0 0 1}$ & $\mathbf{0 . 0 1 6}$ & $\mathbf{0 . 0 0 2}$ & $\mathbf{0 . 0 0 0}$ \\
\hline
\end{tabular}

1.Year/quarter variable has not been included in the table as it was only included as a control variable and significant results are sometimes difficult to explain; but seasonality clearly evidenced.

2. Rate per 100 persons

Notes: Significant results are highlighted in bold 
Table A2 First variant: First Time Offenders committing violent/property crime in relationship to crime-specific prior offenders ${ }^{1}$

\begin{tabular}{|c|c|c|c|c|c|c|}
\hline & \multicolumn{3}{|c|}{ Violent } & \multicolumn{3}{|c|}{ Property } \\
\hline & Coef. & Std. Err. & $P>|z|$ & Coef. & Std. Err. & $P>|z|$ \\
\hline $\begin{array}{l}\text { Lag_Violent/Property } \\
\text { NAOs }\end{array}$ & 0.011 & 0.003 & 0.000 & 0.013 & 0.002 & 0.000 \\
\hline CIPO Violent rate ${ }^{2}$ & -0.098 & 0.022 & 0.000 & 0.024 & 0.021 & 0.244 \\
\hline CIPO Property rate ${ }^{2}$ & 0.078 & 0.019 & 0.000 & -0.020 & 0.017 & 0.235 \\
\hline CAPO Violent rate ${ }^{2}$ & 0.035 & 0.043 & 0.423 & 0.047 & 0.041 & 0.248 \\
\hline CAPO Property rate ${ }^{2}$ & 0.105 & 0.038 & 0.006 & 0.078 & 0.035 & 0.025 \\
\hline \% Males aged 13_15 & 0.016 & 0.017 & 0.354 & -0.014 & 0.016 & 0.362 \\
\hline \% Males aged 16_19 & 0.023 & 0.013 & 0.069 & -0.004 & 0.012 & 0.716 \\
\hline \% Males aged 20_24 & -0.010 & 0.011 & 0.384 & -0.010 & 0.010 & 0.311 \\
\hline \% Males aged 25_29 & 0.003 & 0.011 & 0.790 & -0.003 & 0.010 & 0.775 \\
\hline$\%$ Males aged 30_64 & 0.005 & 0.008 & 0.561 & 0.011 & 0.007 & 0.125 \\
\hline$\%$ Males aged $650 v e r$ & -0.014 & 0.016 & 0.377 & -0.011 & 0.015 & 0.463 \\
\hline \% Females aged 13_15 & 0.011 & 0.018 & 0.532 & 0.001 & 0.017 & 0.963 \\
\hline \% Females aged 16_19 & 0.000 & 0.013 & 0.983 & -0.005 & 0.012 & 0.701 \\
\hline \% Females aged 20_24 & 0.013 & 0.011 & 0.237 & -0.003 & 0.010 & 0.750 \\
\hline \% Females aged 25_29 & 0.013 & 0.012 & 0.281 & -0.021 & 0.011 & 0.061 \\
\hline \% Females aged 30_64 & -0.009 & 0.010 & 0.372 & -0.006 & 0.009 & 0.515 \\
\hline$\%$ Females aged 650ver & -0.014 & 0.011 & 0.205 & -0.022 & 0.010 & 0.023 \\
\hline$\%$ Income deprived & 0.007 & 0.002 & 0.000 & 0.017 & 0.002 & 0.000 \\
\hline
\end{tabular}

1.Year/quarter variable has not been included in the table as it was only included as a control variable and significant results are sometimes difficult to explain; but seasonality clearly evidenced.

2. Rate per 100 persons

Notes: Significant results are highlighted in bold 
Table A3: Second variant: First Time Offenders committing violent/property crime crimes in relationship to deprivation*All Prior offender interactions ${ }^{1}$

\begin{tabular}{lccc|ccc}
\hline & Coef. & Std. Err. & P>|z| & Coef. & Std. Err. & P>|z| \\
\hline Lag_Violent/Property NAO & $\mathbf{0 . 0 1 1}$ & $\mathbf{0 . 0 0 3}$ & $\mathbf{0 . 0 0 0}$ & $\mathbf{0 . 0 1 3}$ & $\mathbf{0 . 0 0 2}$ & $\mathbf{0 . 0 0 0}$ \\
CIPO Rate & 0.028 & 0.026 & 0.280 & 0.006 & 0.024 & 0.794 \\
CIPO *Deprivation & 0.030 & 0.019 & 0.111 & 0.014 & 0.017 & 0.395 \\
CAPO rate & $\mathbf{0 . 0 5 3}$ & $\mathbf{0 . 0 1 9}$ & $\mathbf{0 . 0 0 5}$ & $\mathbf{0 . 0 5 6}$ & $\mathbf{0 . 0 1 8}$ & $\mathbf{0 . 0 0 2}$ \\
CAPO*Deprivation & 0.010 & 0.015 & 0.489 & -0.004 & 0.014 & 0.781 \\
\% Income deprived & 0.061 & 0.034 & 0.075 & $\mathbf{0 . 2 4 1}$ & $\mathbf{0 . 0 3 1}$ & $\mathbf{0 . 0 0 0}$ \\
\% Males aged 13_15 & 0.006 & 0.017 & 0.702 & -0.017 & 0.016 & 0.286 \\
\% Males aged 16_19 & 0.011 & 0.013 & 0.405 & -0.009 & 0.012 & 0.471 \\
\% Males aged 20_24 & -0.016 & 0.011 & 0.159 & -0.012 & 0.010 & 0.253 \\
\% Males aged 25_29 & -0.003 & 0.011 & 0.796 & -0.004 & 0.010 & 0.649 \\
\% Males aged 30_64 & 0.002 & 0.008 & 0.808 & 0.009 & 0.007 & 0.197 \\
\% Males aged 65Over & -0.016 & 0.016 & 0.300 & -0.014 & 0.015 & 0.328 \\
\% Females aged 13_15 & 0.011 & 0.018 & 0.551 & 0.002 & 0.017 & 0.924 \\
\% Females aged 16_19 & -0.005 & 0.013 & 0.679 & -0.007 & 0.012 & 0.580 \\
\% Females aged 20_24 & 0.009 & 0.011 & 0.440 & -0.005 & 0.010 & 0.596 \\
\% Females aged 25_29 & 0.008 & 0.012 & 0.537 & $-\mathbf{0 . 0 2 4}$ & $\mathbf{0 . 0 1 1}$ & $\mathbf{0 . 0 3 8}$ \\
\% Females aged 30_64 & -0.015 & 0.010 & 0.121 & -0.008 & 0.009 & 0.351 \\
\% Females aged 650ver & -0.016 & 0.011 & 0.126 & $-\mathbf{0 . 0 2 2}$ & $\mathbf{0 . 0 1 0}$ & $\mathbf{0 . 0 2 8}$ \\
\hline
\end{tabular}

1.Year/quarter variable has not been included in the table as it was only included as a control variable and significant results are sometimes difficult to explain; but seasonality clearly evidenced.

2. Rate per 100 persons

Notes: Significant results are highlighted in bold 
Table A4: Third variant: Model including splines to identify thresholds ${ }^{1}$

\begin{tabular}{|c|c|c|c|c|c|c|}
\hline & \multicolumn{3}{|c|}{ Violent } & \multicolumn{3}{|c|}{ Property } \\
\hline & Coef. & Std. Err. & $\mathrm{P}>|\mathrm{z}|$ & Coef. & Std. Err. & $\mathrm{P}>|\mathrm{z}|$ \\
\hline Lag_Violent/Property NAO & 0.011 & 0.003 & 0.000 & 0.013 & 0.002 & 0.000 \\
\hline CIPO Rate ${ }^{2}$ & 0.005 & 0.018 & 0.792 & 0.003 & 0.017 & 0.874 \\
\hline CIPO median spline & 0.010 & 0.019 & 0.598 & 0.002 & 0.018 & 0.915 \\
\hline CAPO rate ${ }^{2}$ & 0.024 & 0.043 & 0.582 & -0.066 & 0.042 & 0.114 \\
\hline CAPO median spline & 0.037 & 0.047 & 0.429 & 0.127 & 0.045 & 0.005 \\
\hline \% Males aged 13_15 & 0.007 & 0.017 & 0.671 & -0.017 & 0.016 & 0.272 \\
\hline \% Males aged 16_19 & 0.013 & 0.013 & 0.332 & -0.009 & 0.012 & 0.456 \\
\hline \% Males aged 20_24 & -0.014 & 0.011 & 0.194 & -0.012 & 0.010 & 0.245 \\
\hline \% Males aged 25_29 & -0.002 & 0.011 & 0.820 & -0.005 & 0.010 & 0.597 \\
\hline$\%$ Males aged 30_64 & 0.003 & 0.008 & 0.659 & 0.009 & 0.007 & 0.219 \\
\hline$\%$ Males aged 65Over & -0.014 & 0.016 & 0.356 & -0.014 & 0.015 & 0.329 \\
\hline \% Females aged 13_15 & 0.009 & 0.018 & 0.608 & 0.000 & 0.017 & 0.979 \\
\hline \% Females aged 16_19 & -0.004 & 0.013 & 0.751 & -0.007 & 0.012 & 0.546 \\
\hline \% Females aged 20_24 & 0.010 & 0.011 & 0.357 & -0.006 & 0.010 & 0.582 \\
\hline \% Females aged 25_29 & 0.009 & 0.012 & 0.455 & -0.024 & 0.011 & 0.034 \\
\hline$\%$ Females aged 30_64 & -0.013 & 0.010 & 0.165 & -0.009 & 0.009 & 0.325 \\
\hline$\%$ Females aged $650 v e r$ & -0.015 & 0.011 & 0.159 & -0.022 & 0.010 & 0.023 \\
\hline$\%$ Income deprived & 0.006 & 0.002 & 0.001 & 0.016 & 0.002 & 0.000 \\
\hline
\end{tabular}

1.Year/quarter variable has not been included in the table as it was only included as a control variable and significant results are sometimes difficult to explain; but seasonality clearly evidenced.

2. Rate per 100 persons

Notes: Significant results are highlighted in bold 
Figure A1 Distribution of property and violent crime committed by offenders resident in datazones

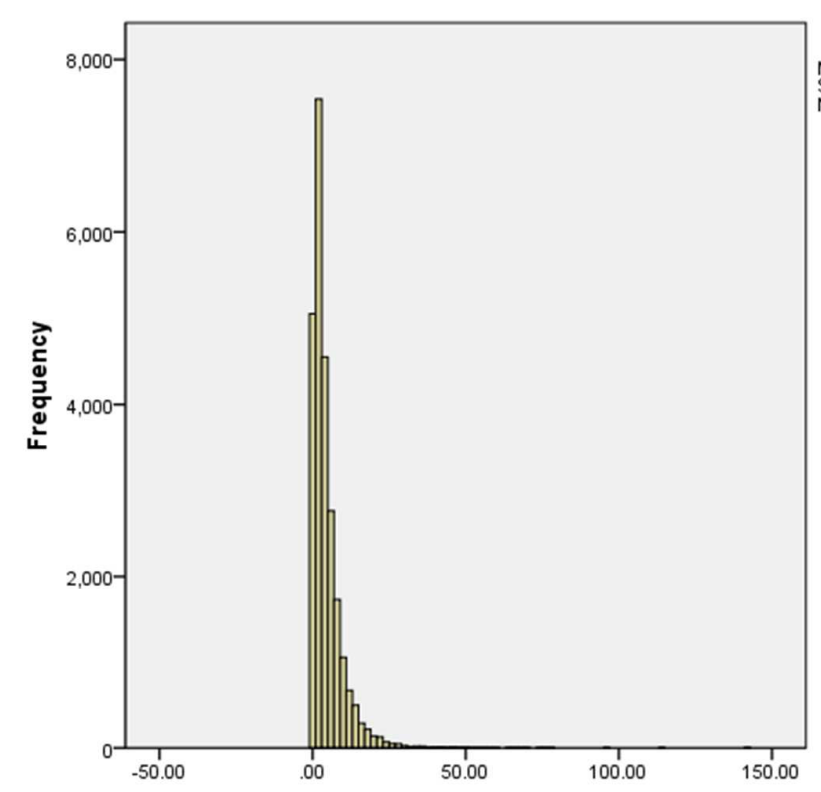

Mean $=4.11$
Stad. Dev. $=5.414$

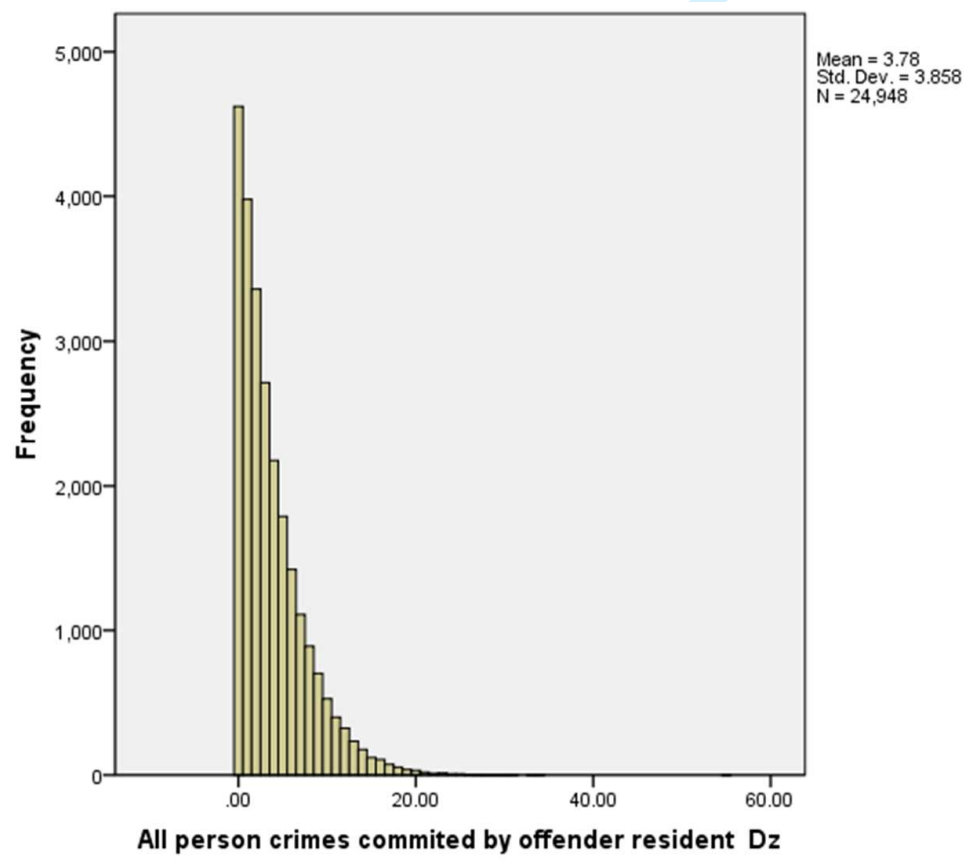

